\title{
ESTUDO EMERGENCIAL A DISTÂNCIA SOBRE O AMBIENTE
}

\section{EMERGENCY DISTANCE STUDY ON THE ENVIRONMENTAL}

\author{
Paulo NOBUKUNI ${ }^{1}$ \\ http://orcid.org/0000-0003-024-2081 \\ Gilmar Mattos CORDEIRO2 \\ http://orcid.org/0000-0003-1716-2607
}

Resumo: O texto trata sobre um trabalho desenvolvido durante o primeiro semestre de 2020, junto à disciplina Recursos Naturais e Análise Ambiental, na 3ª série do curso de Geografia - Bacharelado, em nível de graduação, da UNICENTRO. As aulas presenciais ocorreram apenas em três semanas, no início do período letivo, sendo depois ministradas através do ensino remoto emergencial, devido ao isolamento social, uma das medidas para minimizar os riscos à COVID-19. Em especial por conta de atividades práticas, optou-se por procedimentos que garantissem o caráter dos denominados trabalhos de campo, mas que, ao mesmo tempo, mantivessem a segurança aos participantes, através do afastamento social. O desafio central foi permutar a ida à realidade, quando dos trabalhos de campo, por outra rotina que respeitasse o afastamento social. Dialogou-se sobre como haveria a permuta, optando-se pelo Google Earth Pro. Escolheu-se como recorte a drenagem urbana em Guarapuava, Paraná. A escolha do aplicativo foi considerada acertada, bem como outros itens, abrindo possibilidades para desenvolver a análise ambiental.

Palavras Chave: Geografia. Análise ambiental. Covid-19. Guarapuava.

Abstract: Abstract: This text is about a work developed during the first half year of 2020 in Natural Resources and Environmental Analysis subject, in the third grade on bachelor's degree in Geography at UNICENTRO. The presential classes were attended only in three weeks, at the beginning of school year, being after taught by means of remote emergency teaching, due to social distancing, one of the prevention measures to try minimize the risks of COVID-19. Specially, because practical activities, it has opted for procedures that guarantee the character of those called field works, but, at the same time, that guarantee the safety of the participants, by the means of social distancing. The main challenge was exchanging the departure to the reality, when it referred to the field works, by other routine that collaborate with the social distancing. It has dialogued on how it would be the exchange; it has been chosen the Google Earth Pro. The choice by Google Earth Pro was considered accurate, as well as other items, opening possibilities to develop the environmental analysis.

Key Words: Geography, Environmental Analysis. COVID-19, Guarapuava.

${ }^{1}$ Mestre em Geografia, professor da Universidade Estadual do Centro-Oeste, Guarapuava, Estado do Paraná, Brasil. E-mail nobukuni@unicentro.br.

${ }^{2}$ Graduado em Geografia - Licenciatura, Bacharelando em Geografia, Universidade Estadual do CentroOeste, Guarapuava, Estado do Paraná, Brasil. E-mail gilmarmcor@gmail.com.

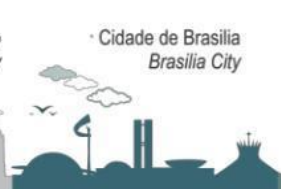




\section{International Journal of Environmental}

\section{Resilience Research and Science (IJERRS)}

Revista Internacional Resiliência Ambiental Pesquisa e Ciência Saciedade 5.ワ Resiliência Ambiental

\section{INTRODUÇÃO}

Este texto trata sobre um trabalho desenvolvido durante o primeiro semestre letivo de 2020, junto à disciplina Recursos Naturais e Análise Ambiental, ministrada na $3^{\text {ạ }}$ série do curso de Geografia - Bacharelado, em nível de graduação, da Universidade Estadual do Centro-Oeste (UNICENTRO), campus Guarapuava, Estado do Paraná, Brasil.

A novidade foi que as aulas presenciais ocorreram apenas em três semanas, no início do período letivo, sendo depois ministradas através do ensino remoto emergencial, devido ao isolamento social, uma das medidas para minimizar os riscos à COVID-19.

Na disciplina referida, em especial por conta de atividades práticas, optou-se por procedimentos que assegurassem o caráter dos denominados trabalhos de campo, mas que, ao mesmo tempo, garantissem a segurança aos participantes, através do afastamento social.

O desafio central foi permutar a ida à realidade, quando dos trabalhos de campo, por outra rotina que respeitasse $o$ afastamento social. Especificamente procurou-se: a) criar um roteiro para que o coletivo de alunos (as) conseguisse levantar dados em campo; b) trabalhar com situações que propiciassem que o corpo discente conseguisse compreender o papel da Geografia, quanto aos seus princípios, bem como ciência que trata sobre a espacialização, a territorialidade e similares; c) verificar os limites e as possibilidades da implantação das atividades propostas.

\section{PROCEDIMENTOS METODOLÓGICOS}

Para atingir os objetivos adotaram-se os procedimentos a seguir:

1‥ Exposição pelo professor e diálogo com e entre os discentes sobre o ensino remoto emergencial, com destaques para o afastamento social, como uma das estratégias para atuar perante à pandemia da COVID-19. 


\section{International Journal of Environmental}

\section{Resilience Research and Science (IJERRS)}

Revista Internacional Resiliência Ambiental Pesquisa e Ciência Saciedade 5.๑ Resiliência Ambiental

$2^{\circ}$. Construção de um roteiro de atividades bem como a definição da maneira de levantar dados de uma localidade a planejar, mas que garantisse o afastamento social.

$3^{\circ}$. Definição de estratégias que propiciassem que o corpo discente conseguisse compreender o papel da Geografia.

4 . Criação de mecanismos avaliativos para a verificação dos limites e as possibilidades da implantação das atividades propostas.

Para o desenvolvimento do $1^{\circ}$ item, especificamente adotaram-se medidas tendose por base o ensino remoto emergencial, conforme denominam Hedges et al. (2020) ao conjunto de atividades no setor da educação, para minimizar os riscos à COVID-19. A caracterização básica deste tipo de sistema educacional é que as atividades são a distância, bem como se adota o mesmo muito rapidamente, por conta da celeridade da propagação da pandemia.

Quanto às especificidades do $2^{\circ}$ item, construiu-se um roteiro de atividades tendose por parâmetro o que indica Bossle (2015), ao discorrer que aplicativos como o Google Earth Profissional, propiciam que se levantem dados de um local em estudo, pois permitem que se navegue até os mesmos, de modo remoto, o que garantiria o afastamento social.

Do roteiro constaram questionamentos sendo eles: a) qual tema estudar? b) qual localidade? Tais reflexões levaram a que se trabalharia com a inundação na região central da cidade de Guarapuava, pois ainda quando as aulas eram presenciais, discutiuse que a prefeitura guarapuavana estava desenvolvendo um plano sobre a drenagem urbana.

No que diz respeito ao $3^{\circ}$ item, definiu-se que se localizaria o polígono de inundação no centro de Guarapuava, pois a localização é um dos princípios da ciência geográfica, conforme esclarecem Martins (2009), Moreira (2013) e Cavalcanti (2019), o que estaria de acordo com o curso de Geografia. 


\section{International Journal of Environmental}

\section{Resilience Research and Science (IJERRS)}

Revista Internacional Resiliência Ambiental Pesquisa e Ciência Saciedade 5.0 Resiliência Ambiental

No que tange ao $4^{\circ}$ item, devido ao programa da disciplina conter a avaliação como um de seus componentes, criaram-se mecanismos avaliativos para possibilitar que se verificasse se as atividades desenvolvidas, seriam insatisfatórias, satisfatórias ou totalmente suficientes, tendo por base os objetivos definidos.

\section{ANÁLISE DA SITUAÇÃO E DAS ATIVIDADES}

Das 15 pessoas que compareceram nas 3 semanas quando das aulas presenciais, no mês de março de 2020, a partir do momento que foi implantado o ensino remoto emergencial, 3 alunos nunca participaram mais, o que perfaz $20 \%$ de desistência.

No final do $1^{\circ}$ semestre letivo, encerrado no dia 23 de novembro de 2020, apenas 6 discentes tinham contato com as aulas, quer seja de modo síncrono (ao vivo) ou assíncrono (acesso em outro momento ao material armazenado), perfazendo em torno de $50 \%$ daqueles que iniciaram o ensino remoto emergencial.

Ao considerar as 15 pessoas que compareceram quando das aulas presenciais, frente aos dados anteriores, teve-se que apenas $40 \%$ tiveram certa regularidade na participação das atividades.

Tabela 1 - Situação discente no transcorrer do 1ํㅗ semestre letivo de 2020.

\begin{tabular}{ccc}
\hline Situação & Quantidade & Percentual \\
\hline Frequentaram as aulas quando do ensino presencial & 15 & 100 \\
\hline Frequentaram aulas quando se iniciou o ensino remoto emergencial & 12 & 80 \\
\hline Mantiveram contato com as aulas até o final do primeiro semestre letivo & 6 & 40 \\
\hline
\end{tabular}

Fonte: Autores

Devido ao final do $1^{\circ}$ semestre letivo ter-se apenas $40 \%$ daqueles que iniciaram o curso procurou-se refletir sobre as causas que levaram a tal realidade. Ao analisar as atividades desenvolvidas com o ensino remoto emergencial compreendeu-se que se garantiu o afastamento social, mas que existiam dificuldades. As principais foram a falta 


\section{International Journal of Environmental Resiliente Research and Scienter (IJERRS)}

Revista Internacional Resiliência Ambiental Pesquisa e Ciência Saciedade 5.๑ Resiliência Ambiental

de acesso à Internet ou a baixa qualidade desta, pois em momento que se efetuaram questionamentos, ainda quando haviam 12 alunos que frequentavam as aulas remotas e emergenciais, apenas 2 não reclamaram de forma mais incisiva sobre a situação. Isto porque, para estas duas pessoas, apesar da rede mundial de computadores apresentar problemas, estes não comprometiam o processo de ensino-aprendizagem, sendo que apenas em torno de $16 \%$ estavam sendo contemplados de modo satisfatório.

Em um momento intermediário da pandemia a universidade conseguiu celulares, mas pela desistência/pouca participação da maioria dos discentes, a situação foi piorando. O desdobramento foi que apenas $40 \%$ continuaram tendo contato com a aula no final do $1^{\circ}$ semestre letivo. Isto poderia ter sido pior, quando se compara ao percentual de satisfeitos (aproximadamente 16\%), pois se fosse mantida a proporção, os dados seriam bem mais piores.

Quanto às atividades, escolhe-se o recorte temático-espacial sobre inundação no centro de Guarapuava, na região Sul do Brasil, no Centro Sul do Paraná (Figura1).

Figura 1- Guarapuava, Paraná, Brasil.

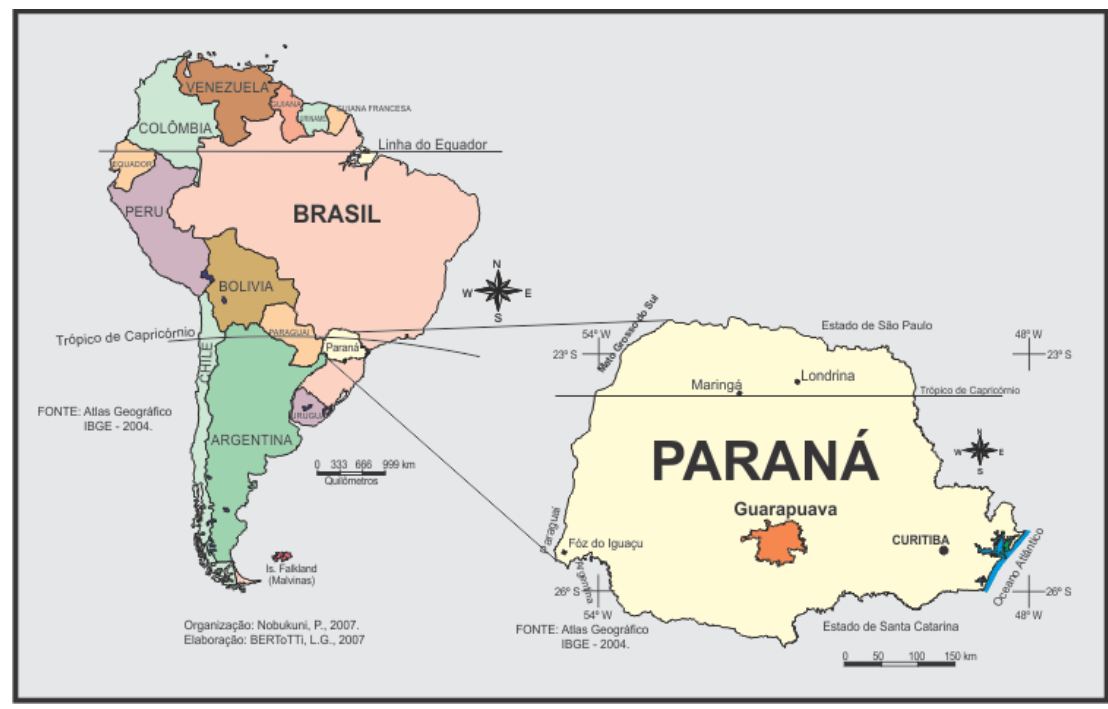

Fonte: Elaborado pelos autores a partir de Nobukuni, 2020.$$
\text { ( }
$$$$
\text { City }
$$ 


\section{International Journal of Environmental Resilience Research and Scienter (IJERRS)}

Revista Internacional Resiliência Ambiental Pesquisa e Ciência Saciedade 5.๑ Resiliência Ambiental

O uso do Google Earth Profissional propiciou o levantamento de dados do local em estudo, pois com a navegação até ele, de modo remoto, além de garantir o afastamento social, foi possível localizar o polígono que sofre inundação no centro de Guarapuava (Figura 2), envolvendo um dos elementos próprios da ciência geográfica, que é a localização.

Figura 2 - Local que inunda em Guarapuava.

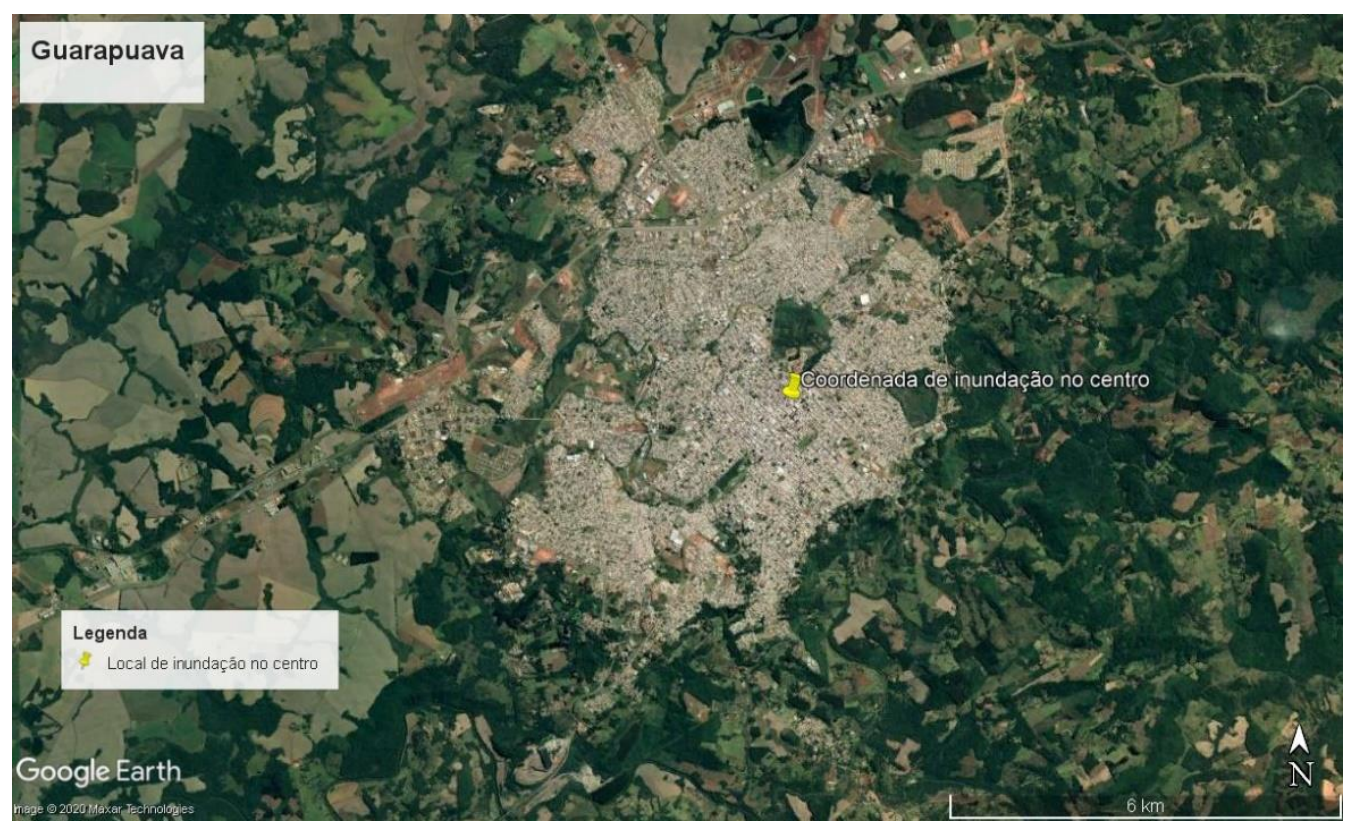

Fonte: Elaborado pelos autores a partir de Nobukuni, 2020.

Além de trabalhar com as coordenadas (latitude, longitude e altitude), de onde inunda, levantaram-se as possíveis localidades que o volume extra poderia ser direcionado para equacionar o problema (Lagoa das lágrimas, Parque do lago e bairro dos Estados), como se tem na tabela 2.

Tabela 2 - Coordenadas UTM das localidades levantadas e suas altitudes em metros.

\begin{tabular}{cccc}
\hline Localidade & Latitude & Longitude & Altitude \\
\hline Ponto de inundação & $7191769.83 \mathrm{~m} \mathrm{~S}$ & $453248.01 \mathrm{~m} \mathrm{E}$ & $1092 \mathrm{~m}$ \\
\hline Lagoa das lágrimas & $7191105.70 \mathrm{~m} \mathrm{~S}$ & $453473.26 \mathrm{~m} \mathrm{E}$ & $1108 \mathrm{~m}$ \\
\hline
\end{tabular}

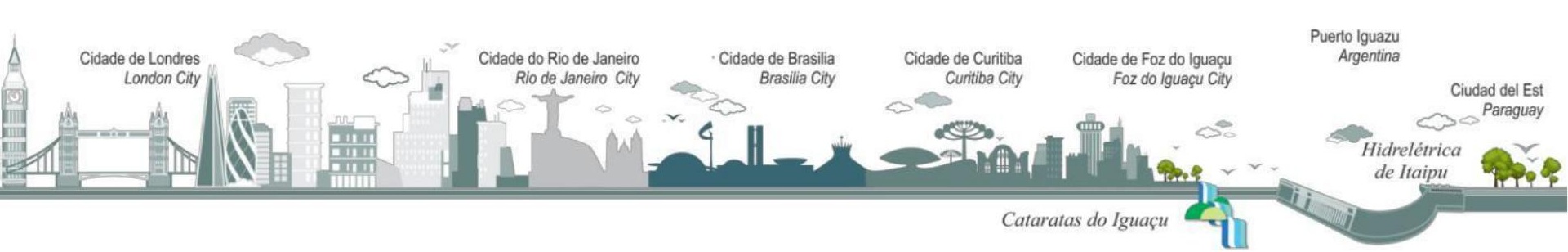




\section{International Jaurnal of Environmental Resiliente Research and Scienter (IJERRS)}

Revista Internacional Resiliência Ambiental Pesquisa e Ciência Sociedade 5.0 Resiliência Ambiental

\begin{tabular}{cccc}
\hline Parque do lago & $7190976.63 \mathrm{~m} \mathrm{~S}$ & $452573.57 \mathrm{~m} \mathrm{E}$ & $1065 \mathrm{~m}$ \\
\hline Bairro dos Estados & $7192632.46 \mathrm{~m} \mathrm{~S}$ & $452060.84 \mathrm{~m} \mathrm{E}$ & $1032 \mathrm{~m}$ \\
\hline
\end{tabular}

Uma das vantagens de trabalhar com o Google Earth Profissional foi devido ao uso da visão vertical em altitude, que auxilia no levantamento de dados (BOSSLE, 2015), em especial porque permite ampliar as possibilidades de estudar uma localidade em análise, como se tem na figura 3.

Figura 3 - Visão vertical em altitude.

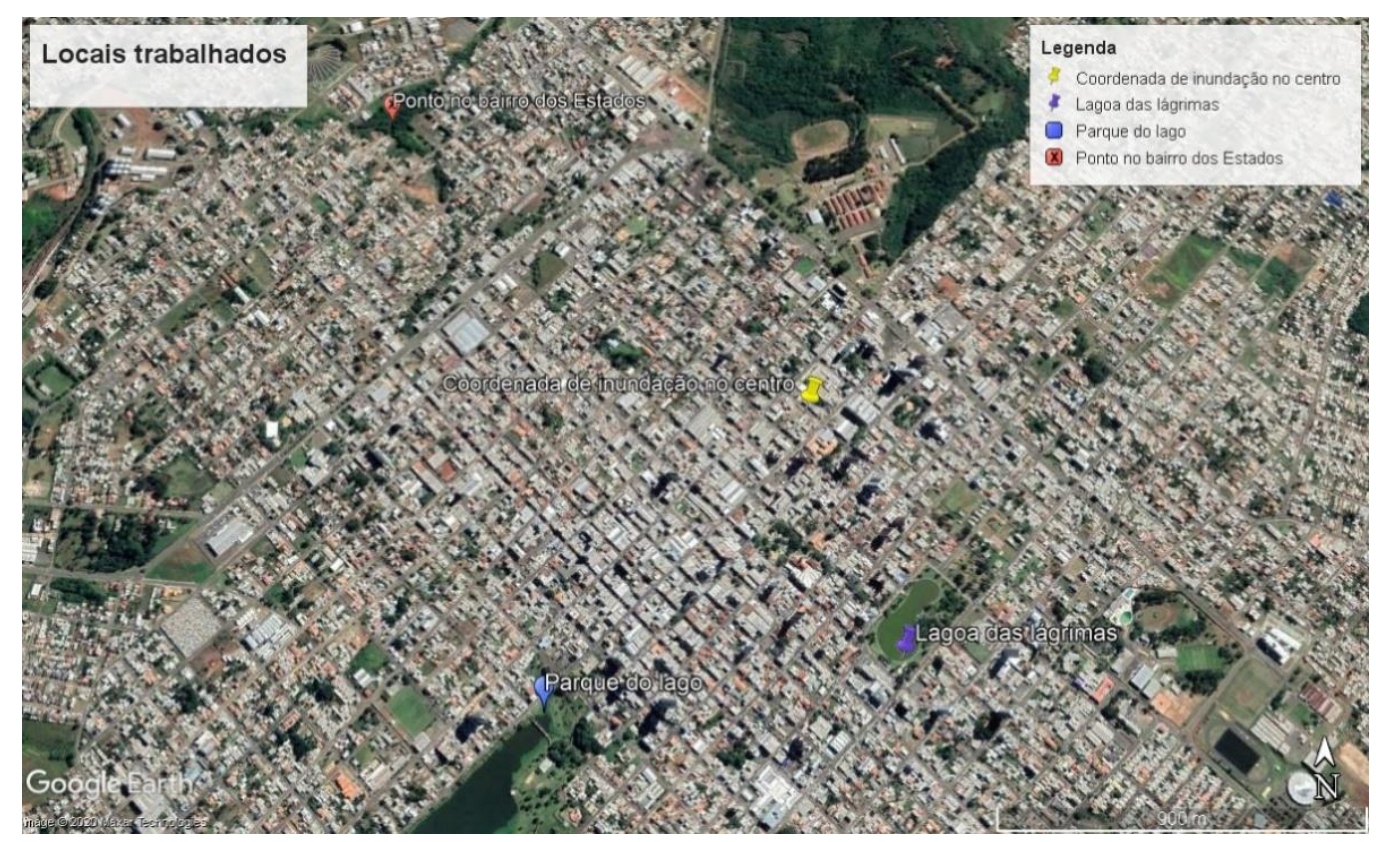

Fonte: Elaborado pelos autores a partir de Nobukuni, 2020.

Quando se soma à visão vertical em altitude às observações na horizontal, que Santos (1998) explicita que é aquela que diz respeito ao que a vista alcança (Figura 4), potencializa-se o poder de análise, pois esta última permite estudar os detalhes.

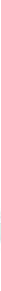




\section{International Jaurnal of Enviranmental Resilience Research and Scientes (IJERRS)}

Revista Internacional Resiliência Ambiental Pesquisa e Ciência Saciedade 5.0 Resiliência Ambiental

Figura 4 - Vista horizontal da área de inundação, no centro urbano de Guarapuava.

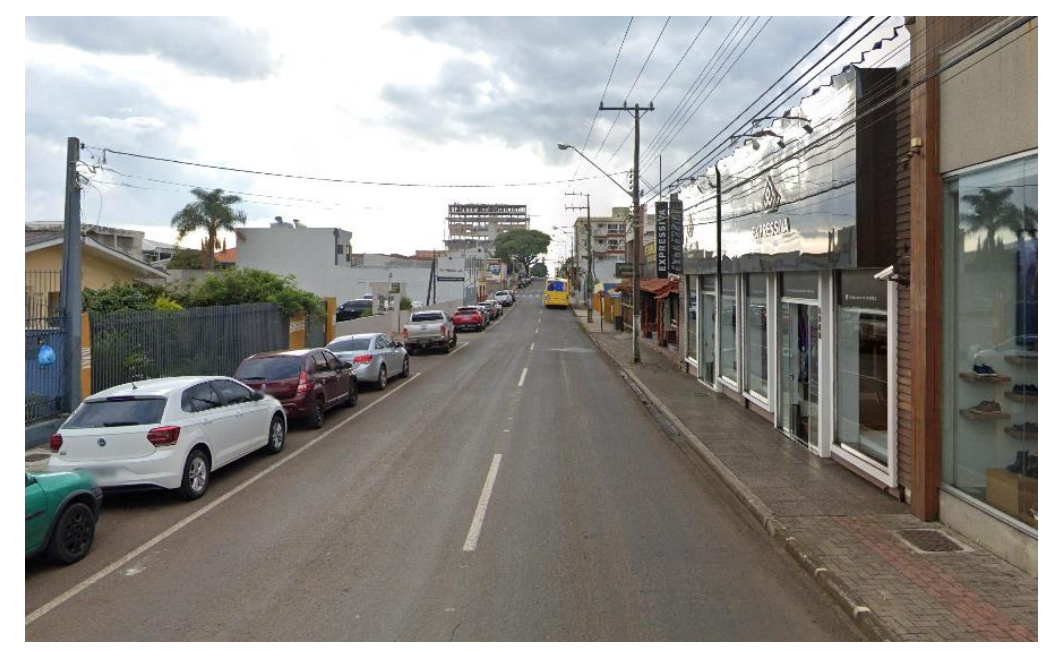

Fonte: Elaborado pelos autores a partir de Nobukuni, 2020.

A escolha do tema referente à drenagem urbana, bem como do recorte nas imediações do centro da cidade de Guarapuava foram essenciais para que se efetuasse o levantamento de forma satisfatória, resultando em boa análise do que foi trabalhado e, consequentemente, dos resultados obtidos, propiciando um plano adequado ao equacionamento das inundações.

O anteriormente foi possível porque os recortes temático e espacial, ao propiciarem focar, auxiliaram em boa compreensão da localidade em análise. Com isto, garantiu-se que as propostas fossem claramente entendidas, tornando-se mais consistentes.

$\mathrm{Na}$ figura 5, em traçado azul, tem-se a proposta prioritária, que constou da abertura de um canal, que extravase o excesso de volume que o leito normal do riacho não suporta quando de chuvas com grande magnitude. 


\section{International Juurnal of Environmental Resilience Research and Science (IJERRS)}

Revista Internacional Resiliência Ambiental Pesquisa e Ciência Saciedade 5.ๆ Resiliência Ambiental

Figura 5 - Proposta de canal, da área de inundação, no centro urbano, em direção ao bairro dos Estados.

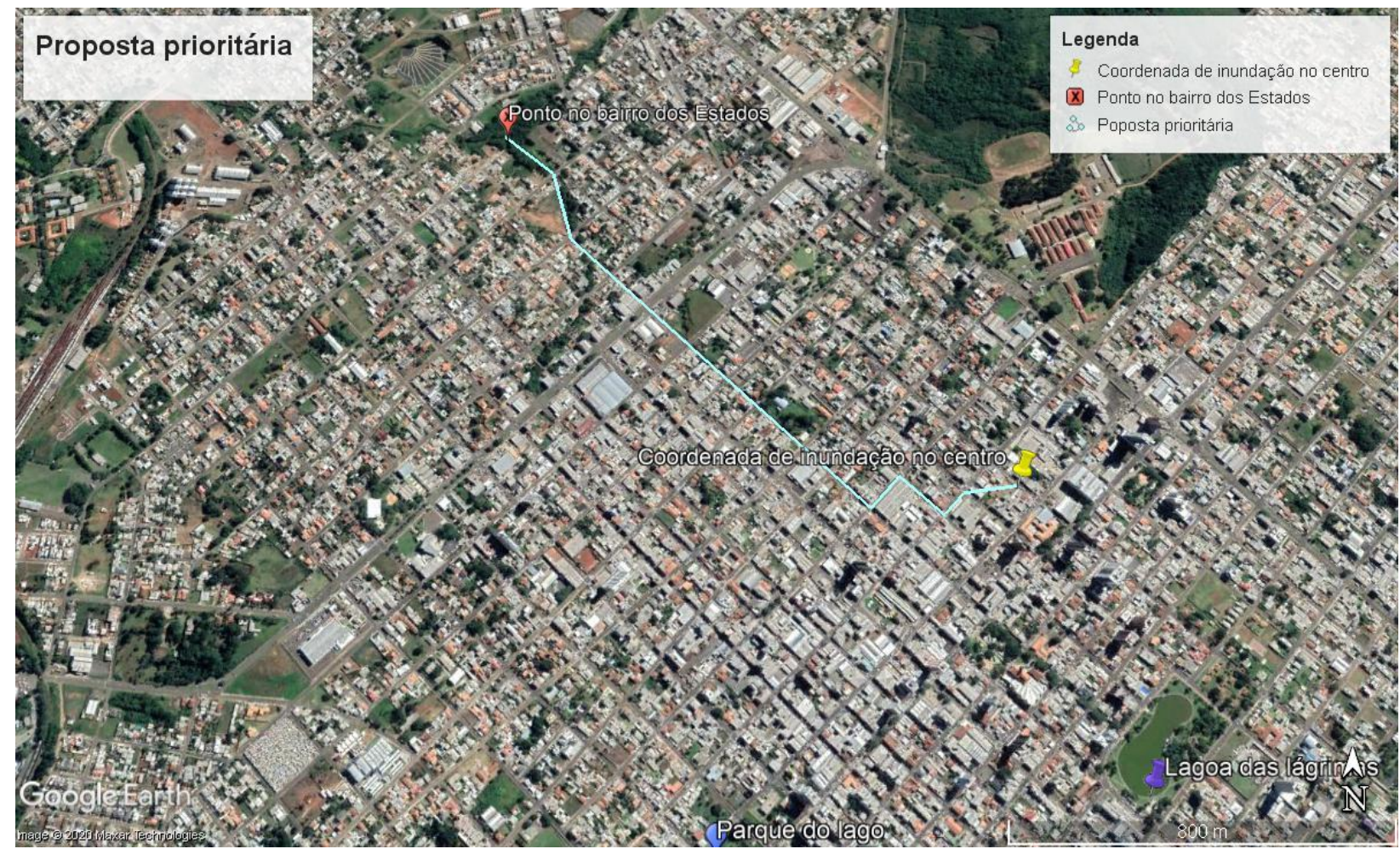

Fonte: Elaborado pelos autores a partir de Nobukuni, 2020.

Apesar de que o ponto de recepção do volume em excesso do bairro dos Estados estar mais distantes do que aquele da Lagoa das lágrimas, ou seja, $1,71 \mathrm{~km} \times 0.64 \mathrm{~km}$, conforme indicou o Google Earth Profissional, totalizando aproximadamente 2,7 vezes, este último fica 16 metros acima do primeiro. Isto torna a proposta onerosa no decorrer do tempo, pois se exigirá bombeamento da água.

O outro local que foi considerado como de recepção do volume em excesso, denominado de Lago do parque, apesar de ficar em um nível inferior, bem como ser menos distante do ponto que inunda, pois há $1,22 \mathrm{~km}$ contra $1,72 \mathrm{~km}$ da escolha prioritária, ou seja, 1,4 vez mais, faz parte de outra bacia hidrográfica, sendo que isto leva à necessidade de escavações relativamente significativas para viabilizar a ultrapassagem do divisor de água de uma unidade de drenagem à outra, somando-se isto à existência de laje rochosa, tornando a obra mais dispendiosa.

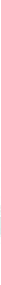




\section{International Journal of Environmental}

\section{Resilience Research and Science (IJERRS)}

Revista Internacional Resiliência Ambiental Pesquisa e Ciência Saciedade 5.ワ Resiliência Ambiental

No caso da escolha prioritária, devido ao riacho estar quase que totalmente urbanizado, propôs-se um canal com traçado bem próximo daquele, onde não existam edificações prediais ou onde elas são menos adensadas, o que implicará passar sob as vias, indo até uma coordenada com menor altitude que aquela do ponto que sofre inundação, ou seja, deverá ir do centro até o bairro dos Estados.

A análise referente à importância da Geografia em estudos ambientais, resultou na compreensão sobre os princípios de tal ciência, pois além da localização, propiciada devido ao uso do levantamento das coordenadas, respondendo onde ficam os elementos estudados, como foram o local de inundação, as possíveis localidades onde se poderia encaminhar o volume em excesso, o mesmo ocorreu quanto à distância, quando se tratou da escala, que é a relação entre a realidade e a representação desta, que no caso foi o mapeamento, resultando na compreensão de qual local ficava mais próximo de onde ocorre a inundação. Destacou-se que o Google Earth Pro, além de permitir a inserção da escala no mapa, também possui ferramenta que calcula distâncias.

Ao tratar da distribuição dos locais estudados, espacializam-se os mesmos, resultando no entendimento da espacialização geográfica. Finalmente, a territorialidade e os desdobramentos desta, foram compreendidos quando se dialogou sobre o direito à uma cidade que ampare as pessoas, o que permite que estas tenham o sentimento referente ao território, de pertencimento, conforme indicam Gómez-Granell e Vila (2003).

Ainda houve a compreensão de que a experiência atendeu ao momento histórico vivenciado nas últimas quatro décadas, onde intensificaram-se as transformações dos lugares, pois o mapeamento digital, como o efetuado na experiência, agilizou a produção da representação da realidade.

Entretanto, compreendeu-se também que se deve atentar quanto ao discurso de que a tecnologia por si resolve as diversas questões, tendo-se por base o que Moreira (2013), esclarece, ao afirmar que apesar da importância daquela, o geógrafo e a geógrafa não devem supervalorizar a técnica. Portanto, considerou-se que ao aparato 


\section{International Journal of Environmental}

\section{Resilience Research and Science (IJERRS)}

Revista Internacional Resiliência Ambiental Pesquisa e Ciência Saciedade 5.ワ Resiliência Ambiental

tecnológico devem-se agregar outros elementos, quer sejam aqueles da ciência de forma geral, bem como os específicos da Geografia, ou seja, o conhecimento.

\section{CONSIDERAÇÕES FINAIS}

Considerou-se que a avaliação das atividades desenvolvidas, ao ter por base os objetivos propostos e o cumprimento deles, bem como os procedimentos adotados, inclusive verificando os resultados obtidos, foi algo extremamente importante, pois permitiu discernir o que foi positivo e o que pode ser melhorado.

Ficou patente que o Google Earth Profissional tem limites, como é o caso de apresentar erros, em especial quanto à tomada de altitudes, mas que estes não comprometeram a essência da análise ambiental, pois o aplicativo permitiu levantar os dados, que após sistematizados, ofereceram informações que propiciaram propor um plano ao tema tratado.

Ao ordenar a experiência sobre a produção do trabalho de análise ambiental, correlacionando-a com a COVID-19, compreendeu-se que a atividade executada auxilia no enfrentamento àquela, em especial quanto ao isolamento social, pois pode ser efetuada a distância.

Apesar de não constar da ideia inicial, a partir do estudo efetuado, ocorreram desdobramentos, pois se iniciaram outros trabalhos, como foram aqueles referentes às diversas medidas à montante da localidade que inunda, sendo exemplos a instalação de cisternas, lagos rasos e similares, já que existem áreas onde estes podem ser utilizados.

Tais estruturas poderão reter e infiltrar a água, minimizando as inundações em épocas chuvosas, bem como oferecer tal líquido na ocasião que as chuvas forem escassas, pois ele fica armazenado no solo e abaixo deste.

Também ocorreram outros desdobramentos, como foi o caso da iniciativa de analisar outra área que inunda, mas que fica em locais extremamente empobrecidos, que são trechos do Jardim das Américas. Neste estudo, ainda não concluído, foi possível 


\section{International Journal of Environmental}

\section{Resilience Research and Science (IJERRS)}

Revista Internacional Resiliência Ambiental Pesquisa e Ciência Saciedade 5.ワ Resiliência Ambiental

compreender que apesar de ele tratar da drenagem urbana, tem outra dinâmica no que diz respeito aos processos naturais, bem como aos grupos sociais que aí assentam-se. Nesta análise em andamento, somou-se outro aplicativo gratuito, o QGIS, um sistema de informação geográfica, para potencializar os trabalhos sobre o ambiente.

Neste local há outras variáveis, tornando o trabalho mais complexo, entretanto mais enriquecedor, pois é necessário propor algo além das obras de engenharia referentes às águas.

Tem que existir também política de remoção das pessoas dos locais que inundam, o reassentamento delas próximo dali, mas que seja em terreno seguro. Ainda é necessário gerar trabalho e outras medidas que propiciem um território prenhe de democracia.

Pode-se afirmar que o trabalho aqui proposto, que se constituiu em um projeto piloto, abriu a possibilidade de estendê-lo a outros locais, inclusive além de Guarapuava, propiciando abranger outras escalas, bem como adequá-lo à realidades diversas.

AGRADECIMENTO: os autores agradecem ao Centro Universitário de Estudos e Pesquisas sobre Desastres - CEPED/UNICENTRO, sendo este uma representação do CEPED/PR, de cunho estadual, estabelecido em Curitiba.

\section{REFERÊNCIAS}

BOSSLE, R. C. QGIS e geoprocessamento na prática. São José dos Pinhais : Íthala, 2015. 2332 p. CAVALCANTI, L. S. Pensar pela Geografia: ensino e relevância social. Goiânia : C\&A Alfa Comunicação, 2019. 232 p.

GÓMEZ-GRANELL, C.; VILA, I. (Org.) A cidade como projeto educativo. Tradução de Daisy Vaz de Moraes. Porto Alegre : Artmed, 2003. 129 p.

HODGES, C. et al. The difference between emergency remote teaching and online learning. Educause review, 2020. Disponível em: <https://er.educause.edu/articles/2020/3/the-difference-betweenemergency-remote-teaching-and-online-learning.

MARTINS, E. R. Pensamento geográfico e Geografia em pensamento. In: KATUTA, Â. M. et al. (Org.). Geografia e mídia impressa. Londrina : Moriá, 2009. p. 13-35. 


\section{International Journal of Enviranmental Resiliente Research and Scienter (IJERRS)}

Revista Internacional Resiliência Ambiental Pesquisa e Ciência Saciedade 5.ๆ Resiliência Ambiental

MOREIRA, R. Pensar e ser em Geografia: ensaios de história, epistemologia e ontologia do espaço

NOBUKUNI, P. Análise Ambiental com uso do Google Earth Profissional. Banco de dados.

Laboratório de Geografia, Planejamento e Gestão Territorial. Guarapuava: UNICENTRO, 2020. 1 DVDROM.

SANTOS, M. Metamorfoses do espaço habitado. Fundamentos teóricos e metodológicos da Geografia. São Paulo: HUCITEC, 1998. 136 p. 